\title{
Elementos esenciales que guían a profesionales que se inician hacia el diseño de un modelo de orientación'
}

\section{Essential Elements to Guide Novice Professionals in the Design of an Orientation Model}

\author{
Zoila Rosa Vargas Cordero² \\ Colegio de Profesionales en Orientación \\ San José, Costa Rica \\ ZOILA.VARGAS@Ucr.ac.cr
}

Recibido 23 de abril de 2013 • Corregido 25 de setiembre de 2013 • Aceptado 01 de octubre de 2013

\begin{abstract}
Resumen. En el presente artículo se fundamenta lo que fue una clase expositiva presentada por la autora, en un curso taller de desarrollo profesional, dirigido a estudiantes de la carrera de Orientación. En él se exponen los elementos básicos que considera deben tomarse en cuenta para obtener un diseño de su propio modelo de trabajo, visto este como referente que guíe la labor orientadora, ya sea de práctica supervisada o de inicio en el quehacer profesional. El artículo trata, de manera general, cada elemento incluido en el diseño, por lo que se presenta un recorrido que inicia con la importancia de conocer la filosofía general que enmarca el ámbito en que se ejerce la orientación. Luego se describe, en forma resumida, el paso a paso desde cada referente teórico práctico, y se incluye el tema ético que responde a la necesaria conducta ética que guíe las obligaciones de todo profesional y al cumplimiento del código que regula el comportamiento esperado. Se termina con una breve revisión de las actitudes necesarias de la persona profesional y el rol asumido en diferentes ámbitos de trabajo. Se tiene como propósito final ofrecer a las poblaciones que se inician en este quehacer profesional una forma guiada que les ayude a desarrollar la pericia para adjudicarle a su práctica un posicionamiento epistemológico.
\end{abstract}

Palabras claves. Diseño, modelo, orientación, principiante, desarrollo profesional.

Abstract. This article is based on a class taught by the author in a Professional Development

1 Este documento y sus contenidos han sido desarrollados por la autora a partir de una posición personal adquirida desde su experiencia docente, profesional y práctica. Responde a una exposición realizada en un salón de clase y dirigida a estudiantes que terminan el tercer año de formación como profesionales en orientación.

2 Magister Scientiae en Educación con énfasis en Administración Educativa de la Universidad de Costa Rica, y posee otra Maestría en Psicología Grupal, licenciada y bachiller en Ciencias de la Educación con énfasis en Orientación, también de la UCR.. Ha escrito diferentes artículos y dirigido tesis de grado y posgrado sobre temas actuales de la orientación y la administración educativa. Se desempeñó como Directora de la Escuela de Orientación y Educación Especial. Dentro de sus labores se ha destacado como docente en el área de la orientación personal, vocacional y grupal en la sede central de la Universidad de Costa Rica y en las sedes regionales de esta misma casa de estudios. Es colaboradora en la dirección de trabajos finales de graduación de la Maestría en Orientación, unidad con la que colaboró impartiendo cursos de orientación, e investigación. Actualmente es miembro de la Junta Directiva del Colegio de Profesionales en Orientación. 
workshop addressed to students majoring in Counseling. The paper includes basic elements that must be taken into consideration to prepare the design of a work model, which should be used as the referent to guide the counseling process for interns as well as for new professionals. The article provides a general overview of each element in the design, including the importance of knowing the general philosophical framework of the Counseling field. It briefly describes the step-by-step process to be followed from each theoretical and practical referent. In addition, it includes the ethics component required to promote the ethical performance of duties of every professional and the compliance with the code ruling the professional's expected behavior. A brief review of the necessary attitude of professionals is included at the end as well as the role to be taken in the different areas. The article is aimed at offering novice professionals with a guide that will help them develop the expertise necessary to add an epistemological positioning to their practice.

Keywords. Design, model, counseling, novice, professional development.

El desarrollo profesional es un proceso que evoluciona con el tiempo, con la actitud y el empeño personal en conseguirlo. Cuando una persona se inicia en el campo laboral, pueden ocurrir varias cosas, entre ellas que presente bajas destrezas de inserción o de autoestima profesional, lo cual le provoque falta de claridad e incertidumbre acerca del quehacer inmediato. Para Montané (1993), poseer suficiente conocimiento no significa madurez ocupacional. Esta es una razón para reafirmar la necesidad de presentar, para todo profesional en su iniciación o en cualquier momento que lo requiera, una guía para la construcción de su propio modelo de trabajo que le sirva como referente para su accionar.

Lo que presento y explico aquí puede verse como una guía, un esbozo o solo como pautas que le permitan, con base en sus conocimientos teóricos y prácticos adquiridos, identificar y definir sus propios métodos, estrategias y técnicas. No pretendo que sea visto como un modelo rígido e inflexible, que podría encasillar o limitar sus posibilidades de innovación y creatividad.

Con este planteamiento intento que cada estudiante trate de conceptuar y construir lo que vendría a constituir la propia posición epistemológica, entendida como la relación que establece el sujeto con el objeto o los objetos de conocimiento para poder describir la forma como se produce y obtiene el conocimiento (Martín y García, 2009), de manera que, con base en ello, la persona pueda tomar seriamente la situación por tratar y no inventar una medida por medio de la especulación, como ya había sido señalado por Piaget (1970). De ahí que planteo una guía como recurso metodológico que contribuya a incluir y ordenar los elementos esenciales por contemplar en una propuesta que favorezca el trabajo práctico orientador y lo integre con la teoría y el método. Como personas que en un futuro cercano serán profesionales que incursionan en el campo laboral, con ayuda de este planteamiento, sabrán establecer la relación existente entre los conocimientos teóricos adquiridos, para trasladarlos a situaciones prácticas, de manera que logren dar respuestas pertinentes y de calidad a las necesidades que presentan las personas orientadas en sus diferentes contextos. Es sabido el significado de la 
posición epistemológica y de qué se trata; también, la importancia de estar al tanto del ámbito y contexto en que se labora.

\section{La política según el ámbito en que se ejerce}

Inicio esta propuesta de guía con pautas para un modelo de trabajo, fundamentalmente, con lo que todo profesional en el campo de la orientación debe saber al respecto, esto es, la importancia de conocer, desde un nivel macro, cuál es la guía filosófica o el marco político que dirige el quehacer, según el ámbito en que se ejerza. A saber, en el Ministerio de Educación Pública existe una política educativa dictada desde noviembre, 1994, cuyo marco jurídico "lo constituye la Constitución Política de Costa Rica y la Ley Fundamental de Educación" (párr. 3), de lo cual se debe tener conocimiento y respetar. "En concordancia con una visión integral de ser humano, la política educativa se nutre de tres visiones filosóficas": la dimensión humanista, la racionalista y la constructivista, tal como lo dicta la Política educativa hacia el siglo XXI (MEP, 1994, Componentes, párr. 1).

Menciono especialmente el campo educativo, porque es en ese sector en el que mayoritariamente se contratan profesionales de orientación; no obstante, en la actualidad ha crecido la demanda de este profesional en otros ámbitos, entre ellos, el Instituto Nacional de Aprendizaje; el Ministerio de Justicia y Paz, que abarca el sistema penitenciario; el ejercicio liberal, además de otros campos de trabajo que cuentan con menor número de profesionales contratados. Todos ellos, espacios laborales que también poseen su filosofía y políticas necesarias de conocer.

Una vez clarificada la filosofía o política constitucional, se debe pasar a conocer la institución designada para laborar o aquella que contrata, según sea el caso; además de algunas particularidades de lo que eso involucra.

\section{La institución y su filosofía}

Toda institución o empresa posee una filosofía y política propia. La persona inserta en esa tiene que conocer su filosofía y con cuál ideología se trabaja en ella. La visión, misión, objetivos, políticas y normas.

No todas las instituciones tienen definidos estos elementos. Algunas instituciones han establecido principios, creencias, objetivos y lemas claros que utilizan como estrategia de difusión institucional y compromiso mutuo entre actores del contexto. Otras incluyen la misión y la visión, cuyo fin es lograr cumplir el mismo principio que estos dictan, con la población que conforma la totalidad de actores en esa comunidad estudiantil, laboral, social o empresarial. Una vez insertos como profesionales en una institución, se asume trabajar con la filosofía correspondiente, en conjunto con todas las personas involucradas, sean colegas, educandos, 
padres, madres u otras, hacia la obtención de los objetivos institucionales. En otras palabras, ese grupo de personas forman una comunidad que, por medio de su desempeño profesional, pretende conseguir, en el campo laboral, lo que promueve, divulga y proyecta la institución.

Luego, a un nivel individual, la persona profesional en orientación debe ser consciente del qué, el cómo y el para qué de su función orientadora, de manera que se posesiona en un lugar epistemológico que resulta de la relación que establece con el objeto de su conocimiento y comprensión de su propia filosofía personal.

En resumen, es importante estar al tanto de los planteamientos básicos de la política educativa o similares; se hace necesario familiarizarse con las directrices provenientes de un marco jerárquico establecido. Por ejemplo, ministerialmente, podría ser del Departamento de Orientación Educativa y Vocacional del Ministerio de Educación Pública o de la Jefatura Nacional de Orientación de la Dirección General de Adaptación Social del Ministerio de Justicia y Paz o, en su defecto, las Juntas Directivas, en aquellas instituciones que así se administren, o jefaturas directas en otras. Luego, es pertinente ubicarse en una dimensión menor, que sería la filosofía y políticas institucionales, para pasar a definir la filosofía personal, fundamentada en el conglomerado de conocimientos teóricos, metodológicos, técnicos y prácticos adquiridos durante su formación profesional, que contribuyan en la construcción de la posición epistemológica con el fin de que esta guíe su quehacer como profesional de orientación y realice las intervenciones orientadoras con claridad, dominio y eficiencia en la consecución de los propósitos.

\section{La filosofía personal}

Cada estudiante o profesional debe concretar la concepción filosófica de ser humano que posee y de su creencia del ser persona, pues a partir de esa conceptuación se establece la relación orientadora, cuya premisa general es promover el desarrollo integral y el bienestar de la persona que se orienta. Esta revisión conceptual es un ejercicio constante y útil en el proceso de formación profesional, es importante continuar en este análisis de la misma forma que se ha tenido que elaborar su propio concepto y significado de orientación. El proceso de formación profesional induce a concebir y atribuirle significado a la orientación, a la persona y al sentido de vida, así como a visualizarse en su rol de profesionales en la relación orientación - persona - proceso.

Clarificar lo que constituye la orientación como disciplina y comprenderla como profesión es lo que inicialmente va a dirigir el accionar profesional, aunado a otros elementos, entre ellos es indispensable el concepto de persona. Esto tiene una connotación, un significado y un significante para cada persona profesional, determinantes en la relación orientadora.

Es importante la creencia y el convencimiento de que ese marco referencial, que han podido construir conceptual y epistemológicamente, responde al significante asignado, a lo que consiste en sentirse profesional en orientación y, de esa manera, disponerse a conjugar todos los componentes que además le ratifiquen un desempeño ético. 


\section{La orientación}

En Costa Rica, la orientación como disciplina que estudia aspectos fundamentales del desarrollo humano ha logrado un amplio avance en sus fundamentos teóricos, epistemológicos y prácticos. La Orientación se ha distinguido por tres grandes áreas de desempeño: la orientación educativa, la vocacional-ocupacional, y la personal-social. Además, la orientación familiar, que se contempla como otra área más que favorece la cobertura de atención, para darse cuenta de las características de la familia de procedencia de cada persona y ejecutar programas o procesos relacionados con la educación y desarrollo de sus miembros. Cada una de estas áreas posee su propio fundamento teórico, que todo profesional de la orientación debe conocer antes de la inserción en el ámbito laboral y desempeño de sus funciones. No obstante, se acota que la orientación ha trascendido estas áreas como lo dejan ver algunos autores, entre ellos Gordillo (1988) y Gavilán (2007) que refieren a otras áreas, pues existe un amplio ámbito laboral en el sector público y en el privado.

La orientación en Costa Rica se inició como práctica profesional en los colegios de segunda enseñanza en el año 1964, para atender, concretamente, a la población adolescente, en lo referente a rendimiento académico y ajuste al medio. Por fortuna, su amplio desarrollo la llevó a convertirse en disciplina aplicada, por las características que posee y porque cuenta con lineamientos investigativos y éticos que le han dado todo un cuerpo de conocimientos teóricos, filosóficos, epistemológicos y metodológicos. Con base en ese desarrollo de conocimientos y resultados de investigaciones propias de la orientación, en la actualidad se puede conceptuar como una disciplina con identidad propia. Posee un historial de desarrollo que la sitúa en un lugar profesional, pues dispone, en el sistema de la educación superior, de una propuesta curricular idónea para la formación de profesionales en orientación.

El objeto de estudio son los procesos propios del desarrollo del ser humano y el sujeto de trabajo, las personas, por lo tanto se necesitan aportes teóricos provenientes de diferentes teorías y disciplinas que convergen en un mayor conocimiento de la compleja y cambiante realidad de estas, lo cual hace que los modelos se traslapen. En otras palabras, el proceso orientador no puede ser estandarizado ni homogéneo, puesto que el ser humano es cambiante y actualiza el proyecto de sí mismo de manera continua desde que nace hasta su ancianidad o muerte. Lo que sí hace esta profesión es educar para la vida, se ampara en un modelo educativo, con una conceptuación que sitúa la orientación como ciencia de la educación donde sujetoobjeto se afectan mutuamente.

Sus fundamentos están particularmente reconocidos en filosóficos, biológicos, sociológicos, antropológicos, psicológicos, económicos y educativos; todos deben considerarse con obligatoriedad en este recorrido de conocimientos para la construcción, al menos, de un diseño de proyecto que guíe la tarea y los contemple. 
URL: http://www.una.ac.cr/educare

CORREO: educare@una.cr

\section{Los principios orientadores}

Al ser la orientación una disciplina que confluye y se interrelaciona con otras, se hace necesario tomar en cuenta algunos principios. No obstante, existen diferentes posiciones teóricas al respecto, por lo tanto, se recomienda ir a las fuentes primarias de información especializada que propongan fundamentos y principios más allá de lo que se muestra en esta exposición.

Para enfatizar la función orientadora, a continuación menciono los principios básicos planteados por Bisquerra (2000) y que pueden favorecer el modelo:

- El principio antropológico contribuye a comprender la orientación dirigida al desarrollo de un mejor tipo de persona, derivada de la fundamentación filosófica de ser humano.

- El principio de prevención trata de reducir el índice de nuevos casos o creer que con el quehacer orientador se pueden prevenir situaciones que afectan a las personas, a los grupos humanos y a la sociedad en general.

- El principio de desarrollo busca desarrollar el máximo potencial de capacidades en las personas, por considerarlas seres en continuo proceso de crecimiento personal.

- El principio de intervención supone la consideración de la persona orientadora como agente de cambio social, que en todo momento debe tener en cuenta el contexto para emplear el método y estrategias especiales que conduzcan hacia la transformación.

Cada principio de los mencionados determina uno de los modelos que a continuación expongo:

Bisquerra (2000) publica una clasificación de modelos para orientación: el modelo de desarrollo, el modelo de programas, el modelo de consulta, y el modelo curativo, de los cuales se puede elegir uno para su utilización. Aclaro, de acuerdo con esta guía, que es recomendable, dentro de lo que ya se ha sugerido, seleccionar un modelo de estos que apoye y determine el tipo de intervención orientadora que ampara el trabajo orientador, así como tomar en cuenta que esa tiene que ostentar la lógica y la consistencia entre una y otra de las pautas seleccionadas. Ejemplo: la consistencia que se debe tener en la construcción del modelo de referencia que cada profesional logre obtener, debe responder a creer en un ser humano potencialmente capaz, que se pueda atender de manera global, lo cual lleva a seleccionar el modelo de desarrollo, amparado al principio básico del mismo nombre.

Por lo que se observa, parece que existe duda acerca de la posibilidad de escoger varios modelos a la vez. Desde esta propuesta sugiero elegir únicamente uno, porque el fin último es que funcione como una guía con pautas para personas profesionales que no han tenido experiencia laboral. Para personas que se inicia como profesionales, lo óptimo es que 
comiencen con lo menos complejo, puesto que iniciarse con lo simple y sencillo conduce a que la misma práctica sea una escuela en la que el aprendizaje evolucione. Luego, con la acomodación de experiencias, comprenderán que esta les abrirá una gama de opciones que, paulatinamente, podrán variar. Sin embargo, para fortalecerse como profesionales, recomiendo iniciar con un modelo concreto, consistente y práctico con el que puedan ejecutar sus procesos o proyectos adecuadamente, con certeza y previendo complicaciones.

Ante la consulta de si es factible escoger un modelo curativo, reitero que la escogencia del tipo de modelo a seguir es una decisión personal. Si se tiene el convencimiento de que lo mejor es hacer intervenciones terapéuticas de índole curativo, tiene también que creer en un ser humano que requiere ese tipo de orientación que brinda ayuda clínica e intervención técnica. Si esa es su creencia y posee la capacidad profesional para ello, entonces escoge un modelo curativo. En todos los modelos se deben desarrollar procesos de orientación que estudien, analicen y contribuyan a enfrentar las contradicciones y confusiones del diario vivir y las transiciones normativas del desarrollo.

El sujeto de trabajo de este profesional es con el ser humano, por el ser humano y para el ser humano, ya sea en atención individual o con los grupos y colectivos humanos en sus contextos, razón por la que se contempla el principio o fundamento antropológico. Sin embargo, tal como lo he mencionado, esos son elementos que las personas en formación o nóveles en el campo tendrán que ir definiendo poco a poco.

\section{La población}

Otro aspecto por considerar en este ejercicio es el ámbito laboral en que se desempeña la persona profesional, porque delimita la población meta y esto, a su vez, es determinante en el tipo de orientación que se debe ejercer.

Todo grupo poblacional tiene una realidad contextual propia, con su condición socioeconómica y cultural que lo convierte en poblaciones diferentes, algunas más complejas, en relación con nuestra perspectiva y comprensión de la cotidianidad social. Conocer más el contexto obliga a contemplar el multiculturalismo, a comprender la diversidad, los principios del enfoque ecológico y así poder ampliar nuestra visión de mundo, de manera que se pueda dar cobertura a cada realidad psicosocial y afectiva, pretendiendo orientar mejor, al tomar en cuenta esa diversidad y el sentido de vida de la comunidad en que se realiza el quehacer profesional.

La orientación refiere a un proceso permanente a lo largo de toda la vida; esto conlleva a una pretensión de contextualizar socio-demográficamente la etapa en que se encuentran las personas que se orientan -sean infantes, adolescentes, o personas adultas-, para establecer apropiadamente las acciones, técnicas o estrategias que se realizan. Se elabora una caracterización de acuerdo con la edad cronológica, posición socio-demográfica 
(condición social, procedencia, nivel educativo, número de miembros que conforman la familia, es decir, lo que determina una tipología de las personas), la identidad, diferencias individuales, religiosas, ideológicas, etnia, género, orientación sexual, contexto, estilo de aprendizaje y diversidad cultural.

Caracterizar la población es fundamental para definir teorías, métodos, enfoques y temáticas por tratar. Resulta muy usual que sobre este aspecto se presenten dudas acerca del ente responsable de definir la temática.

Más que temática, lo más conveniente es que se atiendan las necesidades de las tareas propias de las etapas del desarrollo, o las necesidades socioemocionales, educativas o vocacionales inmediatas. Si se hace de esta manera, sería la población la que determina la temática. Sin embargo, como ya se ha mencionado, en todo centro educativo o institución existen directrices y políticas, además de una jefatura, dirección u órgano institucional que define y especifica los temas. Y, ya en última instancia, es la persona profesional la que decide al respecto.

En cuanto a la consulta de quién escoge la población que se debe atender, y si esto es competencia de la persona profesional, se podría decir que ese sería el ideal, no lo que ocurre en la realidad de su quehacer. De mi parte sugiero que cuando se está en busca de empleo se escoja dentro de lo posible el ámbito, como una forma para obtener mayor satisfacción laboral. Generalmente, se tiene predilección y gusto por cierto grupo poblacional y, para ser consecuente con su preferencia, puede participar en concursos laborales que conduzcan a obtener su objetivo. En otras palabras, la persona profesional podrá escoger la población que desea atender, siempre que presente sus atestados o currículum vítae en instituciones donde se atienda la población de su preferencia.

Y, en cuanto al tópico por desarrollar con cada población, retomo algo de la experiencia más frecuente en el trabajo realizado por profesionales en orientación. Como ya lo mencioné, se presentan diversas situaciones y en algunos casos se puede elegir el tema, y en otros se debe atender lo que ya está definido. Con base en lo que ha sido más tradicional en el quehacer de la orientación, hago referencia a algunas grandes temáticas; sin embargo, debe tomarse en cuenta que cada una de estas se extiende y ramifica con los subtemas (esto puede observarse en un plan de trabajo anual del Ministerio de Educación Pública), a saber: en sétimo se requiere un proceso de ajuste y adaptación al medio; en octavo la sexualidad es un tema apropiado; en noveno se enfatiza más lo vocacional; en décimo, relaciones interpersonales, de pareja y noviazgo; y en undécimo, el contexto social y la elección de carrera. Además, repito que se deben considerar las necesidades particulares del momento que vive cada población, todo lo cual debe conducir a ejecutar proyectos o procesos orientadores específicos de temas puntuales, según sea el caso.

Ahora bien, reitero una vez más que el objetivo de este planteamiento es presentar solo ideas u opiniones a ser reemplazadas, sin que se dejen de lado aquellos elementos básicos que deben constituir el diseño del modelo de referencia que guíe su quehacer profesional. Busca 
la flexibilidad y en ningún caso pretende fomentar la rigidez, con el fin de que quien lo utilice tenga la oportunidad de construir su propio modelo de manera creativa y con base en sus conocimientos y preferencias conceptuales.

\section{Área de atención}

Otro aspecto fundamental es clarificar aspectos del área específica de la orientación en que se enfatiza la atención. Se planteó anteriormente que la demanda de este profesional se concentra especialmente en el sistema educativo formal, en el sistema penitenciario y en el Instituto Nacional de Aprendizaje, todos con las mismas áreas de atención; sin embargo, la persona profesional debe saber si le corresponde cumplir sus funciones en el área educativa, el área vocacional-ocupacional, el área personal-social o la familiar.

En algunas instituciones se dota de libertad al profesional en cuanto a la escogencia de tópicos temáticos; sin embargo, se tiene que tomar en cuenta que el área de atención se encuentra muy vinculada con la temática y el grupo poblacional con que se trabaja, como ya se mencionó. Por ejemplo, si les corresponde trabajar en un colegio técnico, la orientación se dirigirá a población adolescente, la cual por su caracterización se hace imperativo que su quehacer se dirija hacia las tres áreas de atención, además de ampararse al plan y programa establecido con anticipación en el Ministerio de Educación Pública. Vale aquí una aclaración, ya que por las circunstancias del momento histórico que se vive, el Departamento de Orientación de este Ministerio ha estado en un impasse, que al respecto lo ha perfilado como pasivo en el aporte de las directrices de operación; no obstante, ya se ha retomado su función rectora hacia el colectivo profesional de la orientación. Cada profesional desarrolla los programas institucionales dependiendo de estos y sus criterios personales.

\section{La modalidad por utilizar}

El siguiente paso corresponde a elegir la modalidad por utilizar en la atención orientadora, la cual exhorto a que sea consistente con lo hasta aquí expuesto. Cada área, sea esta vocacionalocupacional, educativa, o personal-social se puede trabajar a partir de la modalidad individual, la colectiva, la personal-grupal o el taller. Paralelamente a la modalidad, existen diversas formas de abordar la orientación; entre ellas menciono tres formas que ayudan en este abordaje del trabajo con grupos: centrado en el líder, centrado en el tema o centrado en el grupo. Formas que se eligen en correspondencia con las características del proceso por seguir. Esto, repito, es una elección que hace la persona profesional por preferencia, comodidad y claridad conceptual. Por ejemplo, el área educativa es propicia para emplear indistintamente la modalidad y la forma de abordar el trabajo orientador. De manera que, la tarea se lleva a cabo con base en un modelo que puede ser el preventivo, cuya finalidad es evitar que se produzca la dificultad, o el modelo de desarrollo que busca fortalecer las capacidades del individuo. 
Por otra parte, para la atención en crisis, problemas circunstanciales, enfrentar situaciones transicionales que afectan a la persona o algún otro aspecto personal necesario de cambiar, se elige una modalidad individual o personal grupal con una intervención más curativa, cuyo propósito es ayudar a obtener bienestar emocional y personal. Estas modalidades se prefieren para esas situaciones, porque permiten mayor reflexión y profundidad, y por ser agentes de cambio. Por medio de intervenciones transformadoras de conductas se acompaña a las personas a enfrentar o modificar aquello que se desea cambiar.

En contraposición, el modelo de consulta favorece la orientación individual en lo que respecta a la atención en crisis, conflictos y relaciones interpersonales; es eficaz para casos especiales y particulares; sin embargo, requiere de mayor organización, distribución del tiempo, horario y logro de los procesos para alcanzar las metas.

Por el alcance y la cobertura, recomiendo la modalidad colectiva o personal grupal, sobre todo en el sistema educativo, penitenciario u otro que brinde atención a poblaciones numerosas, pues es una forma de obtener mayor economía, cobertura y uso eficaz del tiempo; además de favorecer la interacción social y adaptación personal. Es importante mencionar que, en algunas instituciones educativas, a cada profesional de orientación le corresponde atender, en promedio, 250 a 400 estudiantes, lo cual limita el quehacer de la orientación y un alcance total. Estos datos justifican la utilización de la modalidad colectiva.

Todo profesional tiene libertad de elegir la modalidad, lo importante es que su identidad profesional le brinde convencimiento y confianza en la utilización de los métodos que emplea en su quehacer y que estén fundamentados en sus principios teóricos, morales y éticos, de manera que, por sus acciones y desempeño, produzca credibilidad ante la población y la comunidad en que labora, como una forma de mantener una imagen privilegiada y a la vez fortalecer esa identidad.

\section{Enfoques psicológicos para la orientación}

De acuerdo con esta guía, el siguiente elemento por considerar es determinar el cómo cada profesional realizará su intervención orientadora. El objetivo de la orientación es contribuir en el crecimiento y desarrollo del ser humano para que se entienda mejor a sí mismo, su conducta y su relación con los demás, y que, de esta manera, logre asumir responsablemente las tareas propias de la etapa del desarrollo en pro de su crecimiento y madurez emocional. Las técnicas propias del método brindado por los enfoques psicológicos para la orientación permiten entender las conductas y acciones para intervenir en el comportamiento de las personas y grupos humanos. Menciono tres de los enfoques que más se utilizan en la formación de este profesional: el cognitivo conductual, el gestáltico y la terapia racional emotiva conductual. Los principios fundamentales de cada uno de estos enfoques los estudian en los cursos de psicología y profundizan en esta materia en otros cursos de la carrera. 
Amplío la explicación sobre la duda que presentan con los enfoques de la orientación vocacional, estos aportan teoría vocacional. Se tienen teorías como Holland (1959), citado por Holland (1998); Super (1953) y Roe (1951), citados por Osipow (1987), entre otras, cada una posee sus métodos y técnicas definidas para entender el proceso vocacional. La persona profesional se fundamenta en una de estas para dirigir su quehacer en esta área. A la vez, ratifica la conducta humana con los aspectos claves del enfoque psicológico para la orientación. Con el primero se explica el desarrollo vocacional propiamente dicho y la manera operativa concreta; el segundo permite comprender la conducta de la persona, para definir la relación orientadora con esta.

\section{El diseño o planeamiento}

Una vez que hayan elegido los aspectos especificados que formarán parte de su modelo para el ejercicio profesional, se tiene que enfocar en un método específico. Hasta aquí se han presentado varios pasos, a saber: los lineamientos, directrices y políticas, filosofía, propósitos, áreas de atención, modalidad, planes y programas, objetivos institucionales, según sea el caso. El siguiente paso o acción puede denominarse la planificación estratégica, el prototipo de acción, el diseño de la intervención procesual o el planeamiento. Esta acción permite organizarse en la definición de objetivos, temas, calendarización, estrategias, función, tareas y evaluación. Vale aclarar que en el sistema educativo el concepto más utilizado es planeamiento y se presenta de manera anual o semestral. En síntesis, es una acción que desde un lenguaje diferente cumple con un mismo propósito: definir y ubicar lo que previamente han identificado como de su interés (la población con la que se trabajará, el enfoque, las estrategias y técnicas apropiadas para la etapa que se intervendrá, el cronograma y el enfoque evaluador).

\section{La evaluación}

Un último elemento interrelacionado con la práctica profesional es la evaluación necesaria en todo proceso, proyecto o programa. Por eso esta construcción incluye elegir el método evaluativo que se empleará. Por medio de este se pueden hacer las revisiones de los programas, planeamientos o procesos, de las actitudes profesionales y personales asumidas y de los productos o resultados que se obtienen. Resulta fundamental definir el enfoque de evaluación que se utilizará, pues es un medio para mejorar. Para el caso de orientación y de acuerdo con Rotger (1989), se sugiere emplear la evaluación procesual, la formativa y la autoevaluativa entre otras que ya conocen. En todo planeamiento, proceso, proyecto o programa por desarrollar, es importante elaborar un prototipo de acción que constituye el diseño con base en el cual se pasa a la ejecución y luego a la evaluación. Es recomendable culminar con una devolución al grupo o persona del proceso seguido, en la cual se muestren los resultados y logros alcanzados. Luego, procede elaborar un informe final, una sistematización de la experiencia o, al menos, un portafolio, en el que se registren las acciones y se evidencie el papel de la orientación en el desarrollo integral de la persona y la educación para la vida. 
URL: http://www.una.ac.cr/educare

CORREO: educare@una.cr

\section{Actitudes necesarias}

Si bien es cierto, para elegir una profesión se requieren ciertas aptitudes, es imperativo mencionar algunas de las actitudes necesarias para este profesional como un aspecto clave en el desempeño profesional. La ética es vista como una de las actitudes personales necesarias y contemplada como la más importante para llevar a cabo con eficacia, eficiencia y de manera exitosa cualquier proyecto profesional, pues es la que otorga seguridad y confianza en el ejercicio profesional. Menciono, además, otras actitudes requeridas para orientar, como son:

- La actitud crítica: la persona crítica que analiza de manera positiva los eventos, acciones o situaciones permanece en constante revisión y autoevaluación de su quehacer con el fin de mejorar día a día.

- Estabilidad emocional: por trabajar con personas y para mantener el equilibrio y la ecuanimidad ante cualquier adversidad que se le presente, la persona orientadora debe ocuparse constantemente de su desarrollo personal y emocional.

- Sensibilidad: es una actitud necesaria para tratar de entender la situación tal como la está viviendo el otro, sin involucrarnos en ella, solo lograr la empatía necesaria que permita entender, para obtener objetividad y neutralidad al orientar.

- Compromiso y responsabilidad profesional: por ser la orientación una profesión de ayuda, la persona profesional necesita, primero, tener compromiso consigo misma para responsabilizarse de las acciones y conductas personales y, después, con la profesión en pro de cumplir con responsabilidad el compromiso que se asume ante la sociedad.

La conducta basada en principios éticos es vista como una protección, porque es a partir de los deberes morales y éticos de la persona que se mide el cumplimiento de los deberes profesionales, de manera armoniosa con la normativa y reglas que establece el código de ética. Esta es la razón por la que es necesario conocer las implicaciones de nuestro quehacer profesional, desde el punto de vista personal, legal y práctico. Aquí entra en juego el desarrollo moral, los valores y la ética que cada profesional posee, así como el cumplimiento de los deberes profesionales que procuran un desempeño integral en el ejercicio de sus funciones con el acatamiento de las disposiciones de un ente rector que le brinda protección ética y legal, como es el Código de ética profesional, creado por el Colegio de Profesionales en Orientación. 


\section{Rol profesional en diferentes funciones}

Una vez comprendido y definido lo antes mencionado, es obligatorio revisar el rol que se asume, según las funciones que realiza este profesional. Ya se mencionó que en toda institución o empresa existe una jerarquía determinante de funciones y tareas, la cual define la función por ejercer. De manera que se establecen diferentes roles: puede ser coordinador, asesor, director, jefe u otro. Por otra parte, cada profesional que incursiona en un ámbito laboral asume un rol, en el caso propio de la orientación puede ser facilitador, educador, asesor, orientador; roles contemplados en las cuatro grandes funciones de todo profesional: investigación o diagnóstico, diseño, ejecución, y evaluación.

En la actualidad este profesional desempeña diferentes roles en sus ambientes laborales, posee habilidades y destrezas para trabajar efectivamente en diversos campos con intervenciones orientadoras en múltiples y variadas situaciones.

Con respecto a los roles más usuales que desempeña este profesional, menciono una breve descripción solo de algunos de los siguientes: docente, investigador, orientadorfacilitador, coordinador, jefe, evaluador y asesor.

Con base en la realidad conocida, el rol de coordinador tiene una función organizativa, es aquella persona que trabaja como coordinadora de departamento en las instituciones educativas. Otra conceptuación sería la función de coordinar una tarea desde una visión más interdisciplinaria o interinstitucional con diferentes profesionales, instituciones o entidades, según sea el caso.

El rol de facilitador constituye la función más pura de la actividad orientadora, porque facilita que se produzca la reflexión interna. Se desempeña principalmente en todo lo que es orientación individual, personal-grupal, colectiva, y algunos talleres cuando el propósito es facilitar la toma de conciencia y un darse cuenta de la situación o realidad dada.

El rol asumido como asesor, lo presento con dos connotaciones. En orientación es un rol que responde más a una función desempeñada tanto por las personas designadas como asesoras regionales, como las homólogas en las asesorías nacionales en el Ministerio de Educación Pública, lo cual forma parte de la organización jerárquico-administrativa existente. Sin embargo, desempeñan una función con características de planificación y organización de la tarea de sus colegas y, por tanto, una tarea orientadora. Por otra parte, en otros ámbitos encontramos también el rol de asesor, sólo que con la función de asesorar, entendida como una función dirigida a recomendar, proponer u otorgar un dictamen relativo a información, opiniones o impresiones que se brindan de manera técnica sobre una situación o materia, que presenta cierto grado de dificultad, a diferentes instituciones públicas, privadas y a personas.

El rol de educador se asume con base en el principio filosófico, metodológico y de la posición epistemológica de la persona profesional y su filosofía personal, aunado esto al significado que le asigne a ese rol educativo para ejercerlo en orientación. 
La claridad que posea un profesional en relación con los roles y funciones que debe desempeñar en su ambiente laboral fortalece la imagen social e identidad profesional de las personas orientadoras y amplía la cobertura de atención.

Para terminar con estas pautas y pasos a seguir, repito, deben tener presente que mi participación ha estado dirigida a brindar una guía con generalidades, para que cada una de las personas diseñe y construya su propio modelo que delimite su trabajo en orientación. Esta labor, según mi criterio, se basa en una posición epistemológica congruente y consistente con el accionar; esto quiere decir que la plataforma de esta construcción es lo que le dará soporte a la estructura y producto final y, si se tiene seguridad en la posición filosófica y epistemológica, la función surgirá de por sí y en relación con aquella.

\section{Consideraciones finales}

En síntesis, reitero una vez más, que esta es solo una guía para un modelo que he construido a partir del conocimiento, la experiencia docente y la práctica orientadora; la explico paso a paso con el fin de que cada quien empiece a cimentar su propio recorrido de aprendizajes, que le permitan adecuar un modelo de orientación. Pretendo ayudar a quienes deben realizar las prácticas que son requisito en la formación como profesionales o bien a quienes se inician en este quehacer orientador.

Sin embargo, como ya lo mencioné, cada profesional de la orientación debe ser consistente con sus creencias, principios y posturas metodológicas y estas, a su vez, cumplir con su compromiso científico, ético, moral, personal y profesional, que constituyen su posición epistemológica.

Otra razón importante para centrarse en un modelo de trabajo es que este profesional debe asumir gran diversidad de funciones y tareas. Guiarse con un modelo favorecerá su desempeño global al adquirir mayor criterio, responsabilidad, y compromiso científico - social, para rendir cuentas a los superiores, a la población orientada, a padres y madres de familia, a la comunidad y al país en general, a la vez que protege su integridad y probidad profesional. Todos estos aspectos resultan relevantes para la orientación como tal, en vista de que posee diferentes definiciones, con la agravante del desconocimiento de esta como disciplina y como profesión, por parte de las personas de nuestra sociedad que desconoce qué es y qué se hace en orientación.

Sospecho que esta puede ser una forma de normalizar el quehacer y, hoy en día, una condición necesaria para ejercer profesionalmente de acuerdo con una fundamentación epistemológica, que edifique el quehacer de la orientación en Costa Rica, donde la orientación ha experimentado un proceso histórico evolutivo con cambios significativos a lo largo de su existencia, desde el punto de vista pragmático, teórico, metodológico y epistemológico. 
Hacer este ejercicio es una oportunidad para replantear su propio aprendizaje y describir su conocimiento, por esto lo llamo posición epistemológica, porque con base en los planteamientos teóricos, se adquiere un conocimiento propio y básico que le permite, a todo profesional que se inicia, reconstruir e integrar saberes acerca de su disciplina, su profesión, su filosofía y su quehacer, transfiriendo esto a un saber hacer, de manera que gobierna y administra su labor con su propio fundamento. La mayor probabilidad para no perderse en el propio quehacer profesional la ofrece un modelo claro, ágil, práctico y sencillo que les permitirá iniciarse con confianza, seguridad y eficacia en el campo laboral.

Al principio señalé y he enfatizado durante toda la presentación, que, cuando se es inexperto en una profesión, resulta de gran ayuda disponer de una guía que, como esta, especifique aspectos generales por tomar en cuenta, porque el dominio y seguridad del trabajo que debe realizarse, les faculta para proponer objetivos claros y consistentes con sus metas orientadoras por cumplir con diversas poblaciones. Después, cuando adquieren más conocimiento y experiencia, concebirán el quehacer profesional desde una perspectiva diferente, que les obligará a hacer críticas y transformaciones a esta propuesta de modelo inicial.

En síntesis, si el fin último de la orientación es visualizar al ser humano de manera integral y enfatiza en el desarrollo de este y su contexto, es imposible que la función orientadora sea rígida y fijada en un solo enfoque teórico específico de atención. Cada institución es particular en cuanto a la población, sus necesidades, directrices, políticas y área de atención. Sin embargo, se debe tener el convencimiento de que en todo ser humano y grupo poblacional, por ser dinámicos y cambiantes, surgen aspectos propios de otras áreas que deben contemplarse en el quehacer orientador, lo que significa que las áreas de la orientación se traslapan en algún momento de todo proceso, de manera que un proceso o proyecto propio del área educativa no puede dejar de lado la familia, lo personal social y lo vocacional, puesto que la persona es un todo conformado por las diferentes dimensiones del ser.

\section{Referencias}

Bisquerra, R. (Coord.). (2000). Modelos de orientación e intervención psicopedagógica (Cap. 1). Barcelona: Ciss Praxis. Recuperado de http://dialnet.unirioja.es/servlet/libro?codigo=5029

Gavilán, M. (enero-diciembre, 2007). La formación de orientadores en contextos complejos con especial referencia a Latinoamérica. Orientación y sociedad, 7, 1-15. Recuperado de http:// www.scielo.org.ar/pdf/orisoc/v7/v7a04.pdf

Gordillo, M. V. (1988) Manual de orientación educativa. Madrid: Alianza Editorial.

Martín, A. V. y García, J. (2009). El pluralismo metodológico en la investigación educativa: Los supuestos ontológico, epistemológico y metodológico (Cap. 2). En A. V. Martín y M. E. Venegas (Coords.), Investigación y formación. Teoría y práctica de la investigación eductiva en la formación de educadores (Vol. II, Manual de posgrado). San José, Costa Rica: SIEDIN. 
URL: http://www.una.ac.cr/educare

CORREO: educare@una.cr

Ministerio de Educación Pública. (1994). Política educativa hacia el siglo XXI. San José, Costa Rica: Autor. Recuperado de http://www.mep.go.cr/politica-educativa

Montané, J. (1993). Orientación ocupacional. Barcelona: Grupo Editorial CEAC.

Piaget, J. (1970). El origen de las estructuras lógicas y matemáticas según la epistemología genética. (Cap. I y II, Trad. G. L. Piscoya). Columbia, New York: University Press.

Rotger, B. (1989). Evaluación formativa. (Vol. 9 de Serie Educación y futuro). Bogotá: Cincel, Kapelusz.

\section{Cómo citar este artículo en APA:}

Vargas, Z. R. (enero-abril, 2014). Elementos esenciales que guían a profesionales que se inician hacia el diseño de un modelo de orientación. Revista Electrónica Educare, 18(1), 265-280. Recuperado de

http://www.revistas.una.ac.cr/index.php/EDUCARE/issue/current

Nota: Para citar este artículo en otros sistemas puede consultar el hipervínculo "Como citar el artículo" en la barra derecha de nuestro sitio web:

http://www.revistas.una.ac.cr/index.php/EDUCARE/index 